\title{
What Makes Men Attend Early Detection Cancer Screenings? An Investigation into the Roles of Cues to Action
}

\author{
Uwe Matterne \\ University Hospital Heidelberg, \\ Germany
}

\author{
MoniKa Sieverding \\ Ruprecht-Karls-Universität Heidelberg \\ Germany
}

\begin{abstract}
The purpose of the present research was to examine which cues to action prompt men to undergo cancer screenings. The first study sought to identify the cues to action relevant to cancer screening (CS) by conducting structured interviews with 71 men aged 45 to 70 years. The second study investigated the relationships between the elicited cues to action and past CS experience in another sample of men $(N=144)$. Multivariate analyses of variance found significant differences in mean recall of seven out of ten cues by CS participation status. Recall was higher for participants than non-participants. For most cues the largest difference was found between non- and annual participants. Physician's recommendation was most strongly associated with participation status, followed by the recommendation by family members. Information from health insurance providers was recalled more often by regular cancer screening participants. Mean recall of media cues was high across all groups and no significant differences were observed, pointing to a possible saturation effect of information from the media.
\end{abstract}

Keywords: men, prostate cancer, cues to action, cancer screening, early detection, preventive behavior

Men have higher levels of cancer incidence and mortality than women; this disparity is seen mainly as a consequence of their more risky lifestyle and their poorer use of primary prevention strategies (Evans, Brotherstone, Miles, \& Wardle, 2005). Men are also less likely than women to utilize the health care system for preventive purposes, for instance, obtaining health screenings (Courtenay, 2000, 2003). Evans and

Uwe Matterne, University Hospital Heidelberg, Germany; Monika Sieverding, Department of Psychology, Ruprecht-Karls-Universität Heidelberg, Germany.

The German Cancer Aid ("Deutsche Krebshilfe") provided funding for the study described in this paper.

Correspondence concerning this article should be addressed to Monika Sieverding, Department of Psychology, Ruprecht-Karls-Universität Heidelberg, Hauptstr. 47-51, D-69117 Heidelberg, Germany. Electronic mail: monika.sieverding@psychologie.uni-heidelberg.de

International Journal of Men's Health, Vol. 7, No. 1, Spring 2008, 3-20.

(C) 2008 by the Men's Studies Press, LLC. http://www.mensstudies.com. All rights reserved. jmh.0701.3/\$12.00

DOI: $10.3149 /$ jmh. 0701.3

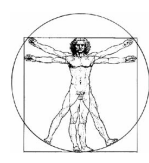


colleagues suggest that gender differences in early detection practices may be a contributing factor to the higher cancer mortality in men. In their review they stated that men engage in self-examination less frequently and are more likely to delay reporting cancer symptoms to a physician.

Although no gender difference emerged in the U.S. with regard to the use of colorectal cancer screening, gender specific cancer screenings show such a difference with lower utilization by men than women (Centers for Disease Control and Prevention, 2004). Similarly, a recent Canadian study found a smaller percentage of men aged 40 to 60 years $(65 \%)$ compared to age-matched women $(79 \%)$ to have discussed or undergone prostate cancer screening or mammography, respectively (McCreary, Gray, \& Grace, 2006). Whereas gender differences in cancer screening participation in the UK appear not as clear-cut and differ by type of cancer screening (Evans et al., 2005), a marked gender gap can be observed in Germany. Since the introduction of a statutory early cancer detection program in 1971, attendance rates have been much lower for men than for women (Altenhofen, 2005). The standard procedure for the early detection of cancer is available to men aged 45 and over consisting of an annual digital examination of the prostate and external examinations of the genitalia. Screening for colorectal cancer starts at age 50 .

To explain which factors influence cancer screening attendance a large body of research has been accumulated, mostly focusing on socio-demographic and variables from social cognitive models of health behavior. An example of the latter is the Health Belief Model (HBM; Becker, 1974; Rosenstock, 1966), an influential model originally developed to find answers to the question as to why people underutilize programs designed to prevent or detect asymptomatic disease (Rosenstock, 2000, p. 78). It assumes health behavior to be a direct function of a number of health beliefs and to be triggered by cues to action. While the main health belief variables (i.e., the major dimensions perceived susceptibility and severity, barriers and benefits) have been subject to a large body of empirical research (see Aoun, Donovan, Johnson, \& Egger, 2002; Harrison, Mullen, \& Green, 1992), cues to action have received less attention in empirical studies. We do, however, think that cues to action play an important role in triggering men's cancer screening participation. Unlike women who are usually reminded and motivated by their gynecologists to undergo cancer screening, most men do not have such a regular contact to a physician. They are also, in general, less motivated to use the health care system (Courtenay, 2000; Evans et al., 2005; Mansfield, Addis, \& Mahalik, 2003), which is why it is important to know what factors function as relevant cues to action to influence men's decisions to undergo cancer screenings. Knowing these cues can assist in the planning of more effective interventions to increase participation rates in men.

The question is thus, "What makes men attend to early detection cancer screenings?" While several studies have investigated the role of cues to action in triggering cancer screening behavior in women (for a review, see Curry \& Emmons, 1994) and the most important cue appears to pertain to physician's advice or influence (Aiken, West, Woodward, \& Reno, 1994; Burack et al., 1994; Finney-Rutten \& Iannotti, 2003; Klug, Hetzer, \& Blettner, 2005; Lerman, Trock, Rimer, \& Jepson, 1991; Nielsen, 1990; Stein, Fox, Murata, \& Morisky, 1992), so far only a very few studies have explicitly ex- 
amined the role of cues to action in cancer screening in men. To our knowledge only two studies have explicitly studied the relationship between cues to action and cancer screening participation in men.

The first by McKee (1994) was designed as an exploratory survey to describe factors assumed to prompt men to participate in prostate cancer screenings. Her sample consisted of 127 men, with a mean age of 66.3 years drawn from prostate cancer screening participants at various hospitals. These participants were asked to complete a questionnaire after having been screened for prostate cancer. Cues to action were assessed by a questionnaire consisting of 13 items derived from a literature review and promotional strategies as provided by screening agencies. Participants were requested to rate the cues' importance in influencing their decision to take part in a prostate cancer screening on a five-point Likert scale ranging from not important (0) to most important (4). Specific appointments, reminder cards, a friend or family member with cancer and newspaper promotion were reported to be the most influential cues to have undergone a cancer screening in the past, based on mean comparisons. Physician's recommendation was ranked seventh out of 13 . However, only two (specific appointment and reminder card) had a mean score of more than two, indicating that all the others were rated as being of below average importance.

The second study by Nivens, Herman, Weinrich and Weinrich (2001) proposed the Cues to Participation theory, stating that prostate cancer screening participation is triggered by exposure to information about prostate cancer and that access to information is affected by socio-demographic variables such as age, ethnicity, education, or income. To test the propositions 1,867 men (a high proportion were Afro-Americans and/or socio-economically disadvantaged) were recruited from a variety of community sites and asked to complete a questionnaire containing items regarding exposure to information about prostate cancer as well as socio-demographic variables. Cues to action items were adapted from the National Health Interview Survey Cancer Control Supplement (Brown, Potosky, Thompson, \& Kessler, 1990). After completion of the questionnaire, participants were given a voucher for a free prostate cancer screening. Uptake of the latter was significantly associated with overall exposure to information about prostate cancer. Univariate regression analyses found information by health care provider and media to be significant predictors of screening uptake. When socio-demographic variables were controlled, only information from a health care provider was significantly predictive of screening participation. The authors also found the amount and the source of information exposed to, varied as a function of socio-demographic variables and suggested to consider these differences when planning interventions aimed at increasing participation rates.

A few questions remain unanswered, though: First, do these cues to action tap all aspects of triggering influence or are there cues to action that have not been included in previous designs? Second, does exposure to cues to action distinguish between participants and non-participants beyond physician's recommendation, as found in Niven et al's (2001) study? Another question not previously addressed, pertains to whether more frequent exposure to cues to action is superior to single exposure to elicit regular cancer screening behavior. For example, Snell and Buck (1996) found multiple in- 
terventions aimed at increasing physician's awareness of their role to convey screening recommendations more successful than single interventions.

Study I sought to address the first question by conducting interviews with men for whom cancer screening is recommended to elicit the relevant cues that triggered cancer screening participation. Study II was designed to address the second and third questions.

\section{Study I}

\section{Method}

Design

Qualitative-exploratory interviews were conducted with a sample of men aged 45 to 70 . The goal was to elicit all possible cues to action relevant for the first time cancer screening (standard procedure for the early detection of cancer). The free answers were categorized and brought into a rank order depending on their respective frequency.

\section{Participants}

Participants for the study were recruited by convenience sampling. Recruitment took place at two registration offices ${ }^{1}$ in Berlin, Germany, one of which was in the former East and the other in the former West Berlin. These sites were chosen to arrive at a representative sample of eligible German men. Men of all social backgrounds have to obtain documents from the registration office at regular intervals. The response rate was high $(90 \%)$.

\section{Materials and Procedure}

Permission to conduct the study was obtained from the heads of the registration offices prior to the data collection. Data was collected using structured interviews. Participants were approached as they waited for their call in the waiting area of the registration offices. The interviewer (U. Matterne) introduced himself as belonging to "Free University of Berlin" and the purpose of the study as being a survey into preventive behaviors of men aged 45-70 years. Participants were assured that the interview was anonymous and that their data would be dealt with confidentially. The interview assessed the participant's age, previous cancer screening experience and the age at

${ }^{1}$ Registration offices issue Identification Cards (IDs) and passports and provide various other services. Germans are obliged by law to register their address. This is also done at the registration office. Each time people move to a new address, they have to tell the authorities. Changes are recorded and the Identification Card is altered to reflect that change. 
which the first screening had occurred. To obtain cues to action for cancer screening, participants with cancer screening experience were then asked to indicate what their first screening participation had been elicited by. Men, who had no experience regarding cancer screenings, were asked to provide reasons for why they had not done so and what they thought could be a potential cue to elicit that behavior in the future. Data analysis was undertaken with ATLAS.ti, a tool specifically designed to aid qualitative data analysis and SPSS for Windows (version 14) for quantitative aspects of the data analysis.

\section{Results}

The mean age of the sample $(N=71)$ was 55.8 years $(S D=7.4)$. Fifty-one $(72 \%)$ of the participants had previous experience of the standard procedure for the early detection of cancer. Twenty (28\%) had never obtained a cancer screening. Responses were categorized by two raters independently. Inter-rater reliability was high (Cohen's Kappa $=.95)$. The vast majority of the 51 participants with cancer screening experience obtained their first cancer screening as a result of a physician's recommendation or discussion with a physician $(n=18)$. Nine participants did so because they had heard about cancer screening through media coverage. In nine cases, screening occurred in response to the recommendation by a person other than a physician. Most of these recommendations came from the wife. The remainder came from friends, acquaintances, colleagues or family members other than the wife. Information from health insurance provider was named by five participants to have triggered cancer screening participation. Two participants named cancer among their colleagues, family or self. Twice, fear of cancer was named as having triggered first time cancer screening participation. Two responses stated that no specific cue had triggered screening participation. These results are displayed in Table 1.

We also looked at the responses of the non-participants $(n=20)$ with regard to potential cues to action for future participation. Half of them $(n=10)$ stated that if symptoms occurred, these would make them consider participating in CS. Symptoms can be viewed as internal cues. However, from a health promotion point of view, reliance on these is unsatisfactory since the effectiveness of interventions is usually reduced once symptoms can be felt by individuals. The remainder did not contain any cues to action that had not already been mentioned by participants.

\section{Discussion of Study I}

The majority of men with a history of the standard procedure of cancer screening were able to name at least one cue to action for first time screening. Out of the 51 men with a cancer screening history, only three were not able to name any. Recommendation by, or discussion with, a medical physician was the source of influence named most often by about a third of the sample, which agrees with findings from other studies in which cues to action were assessed (McCoy et al., 1995; Nivens et al., 2001; Perkins, Sanson-Fisher, Clarke, \& Youman, 1998). Other frequently named sources of influence refer to media coverage, which was also found to be a relevant cue by George 
Table 1

Recalled Cues to Action for First Time Participation in Cancer Screening

Category

Physician's recommendation or

discussion with physician

Media coverage (television, newspapers, radio)

Recommendation by person other than doctor

Information from health insurance provider

Cancer among family, friends, colleagues

Physical Symptoms

Other Cues/Responses

Total
Frequency

Note. Cues to action reported by 51 men, who had attended a cancer screening at least once; multiple responses were possible, "Other Cues/Responses" contains single responses as well as responses not considered to be cues to action.

and Flemming (2004), McKee (1994), Nivens et al. (2001), and Raich et al. (1997) and recommendation by a person other than a medical physician such as the wife or partner, which was also cited by George and Flemming (2004). We also identified information from a health insurance provider as a relevant cue to undergo cancer screenings, a cue, which had not been reported in previous studies. Although McKee (1994) found appointment scheduling or reminder procedures to be the most important cues, none of the participants in our sample recalled these mechanism as relevant triggers of cancer screening participation. (So far reminder procedures for cancer screening have not been introduced in Germany.) Regarding the responses of non-participants about potential cues to action it appears that the majority of non-participants have misperceptions about the value of cancer symptoms calling for measures to alter these by providing adequate information.

In order to validate the issue of relative importance of the respective cues to action and to address the question of whether exposure to cues to action differentiates between men who have attended early detection cancer screenings and men who have never attended early detection cancer screenings, the second study was conducted.

\section{Study II}

\section{Method}

A questionnaire based on the findings of Study I was administered to a sample of men aged 45 to 70 years. The goal of this study was to assess the relative importance 
of each cue to action and whether exposure to cues to action varied as a function of participation status.

\section{Participants}

Again, convenience sampling was used to recruit 144 men. Sixty-five participants were recruited in Berlin as they waited to be admitted to the federal parliament ("Reichstag") and handed an anonymous questionnaire to be completed while waiting. Another 79 participants were recruited in the city of Heidelberg in the main shopping street. The response rate reached $65 \%$.

\section{Materials and Procedure}

Cues to actions. The cues to action that emerged as relevant triggers of cancer screening participation in the interview-study were included in Study II's questionnaire. Two mechanisms appeared to convey the content of a cue to action. These were a) having heard about cancer screening from a particular person or institution or b) having a cancer screening recommended by a particular person or institution. This led to the design of a questionnaire containing two sets of cues to action, consisting of 5 items each. The first inquired about whether the participants had ever received information about cancer screenings from the following people or institutions: Health insurance provider, print media, television/radio, campaign at health fair or a health promotion campaign on the street and/or at a physician's practice. The items of the second set asked the participants to state whether a medical examination for early detection of cancer had ever been recommended to them by one of the following people: physician, friends/acquaintances, colleagues, family members and wife/partner. To the group of "information cues" we included an additional cue to action that had not been explicitly mentioned by the participants in our interview study: a health promotion fair. Over recent years in Germany several health promotion campaigns and fairs have taken place with the goal to increase preventive health behaviors in men (so called Maennergesundheitstage = Men's Health days). These campaigns explicitly aim at serving as cues to action. Hence, we wished to ascertain whether men had had contact with such offers and whether receiving information by means of these health campaigns is associated with cancer screening behavior. The frequency with which each cue to action was recalled was rated on a three-point scale ("never," "once," "more than once").

Past cancer screening behavior. Previous cancer screening experience was assessed by asking the men whether and how often they had attended the standard cancer screening procedure that is offered to men aged 45 and above with the four options "never," "irregularly," "every 2-3 years," or "annually."

Socio-demographic variables. Marital status was measured with a two-point item with the alternatives "living alone" and "living with wife/partner." Education was meas- 
ured with a 4-point item (no school certificate, elementary school certificate, ordinary and advanced certificate of secondary education).

\section{Results}

Mean age of the sample $(N=144)$ was 56.6 years $(S D=7.5)$. Forty-six $(31.9 \%)$ had never, $34(23.6 \%)$ irregularly, $36(25.1 \%)$ every $2-3$ years and $28(19.4 \%)$ annually obtained a cancer screening. Twenty men lived alone and 122 with their wife or partner. Thirty-two $(22.5 \%)$ men left school with an elementary school certificate, 45 $(31.7 \%)$ with an ordinary and $65(45.8 \%)$ with an advanced certificate of secondary education, signifying an overrepresentation of men in the sample who graduated from school on more advanced levels. Microcensus data from the statistical yearbook for Germany states percentages of $43 \%$ for elementary, of $24 \%$ for ordinary and of $25 \%$ for advanced school leavers for the year 2004 (Federal Statistical Office, 2005).

Analogous to Nivens et al. (2001) we tested for possible differences in degree of exposure to cues to action as a function of education. Multivariate analysis of variance detected no significant effects for degree of education on frequency of exposure to the combined cues to action, $F(20,176)=1.46, p=0.10$.

Table 2 illustrates descriptive statistics of and correlations among the cues to actions considered and correlations with CS participation. The highest means were observed for cues from media. The lowest was found for health promotion fair. Correlations among all cues ranged from 0.11 to 0.65 and were all in a positive direction. Most cues were significantly related to each other. The highest correlations between cues and CS participation occurred for physician's recommendation and recommendation by a family member.

We were interested whether there were significant differences in degree of exposure to cues to action a function of CS participation frequency and whether regular (annual) participants reported higher cues to action exposure than less regular participants. To answer these questions we performed two multivariate one-way analyses of variance (MANOVA) to identify significant differences in mean recall of cues to action by CS participation status. The dependent variables were grouped according to the two mechanisms conveying the content of the cues to action (information from and recommendation by a particular source) found in Study I.

\section{Cues to Action I - Information}

In the first MANOVA, with use of Wilk's $\lambda$ significant differences in the combined information cues as a function of CS participation status were observed, $F(15,301)=$ $2.46, p<0.02$, partial $\eta^{2}=0.10$. Follow-up ANOVAs indicated significant differences only in recall of information from health insurance provider and physician as a function of CS participation status. The results from univariate analysis are displayed in Table 3. 
Early Detection Cancer Screenings

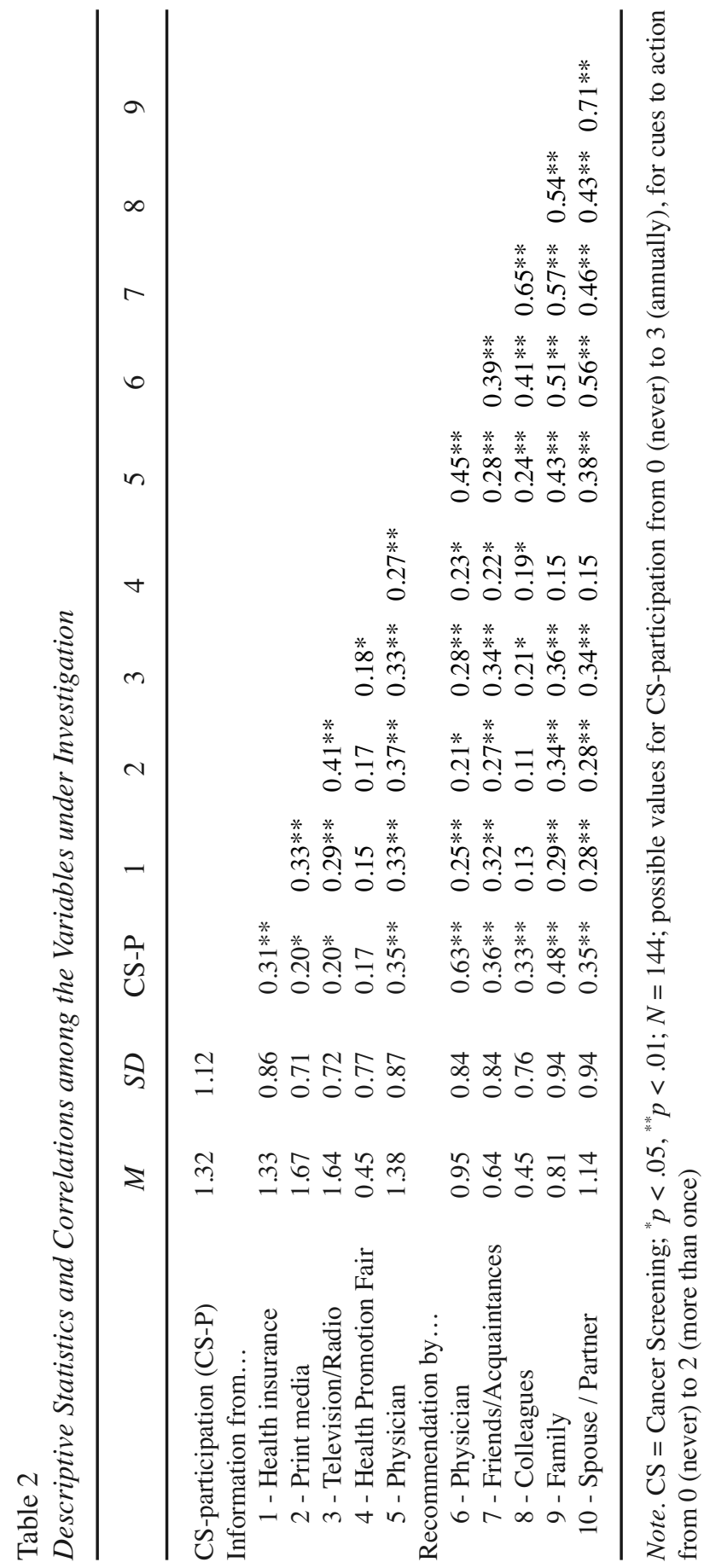




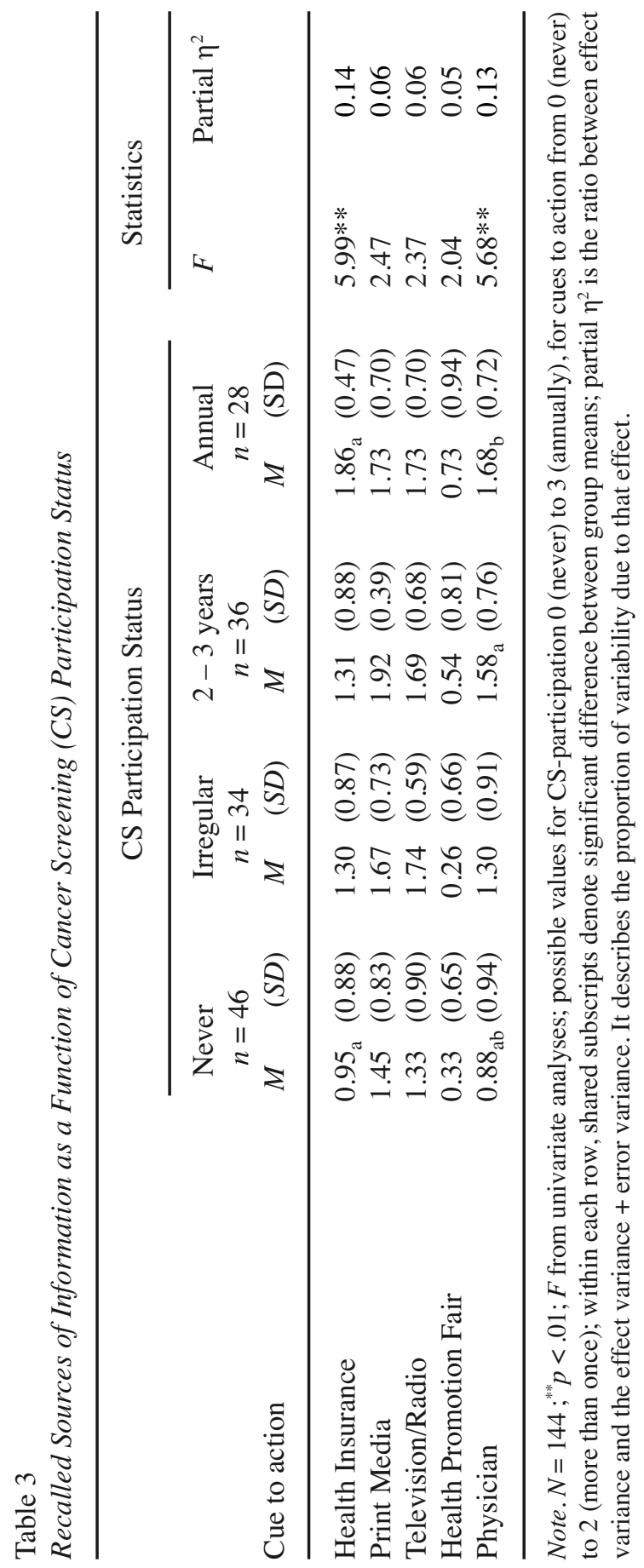


Early Detection Cancer Screenings

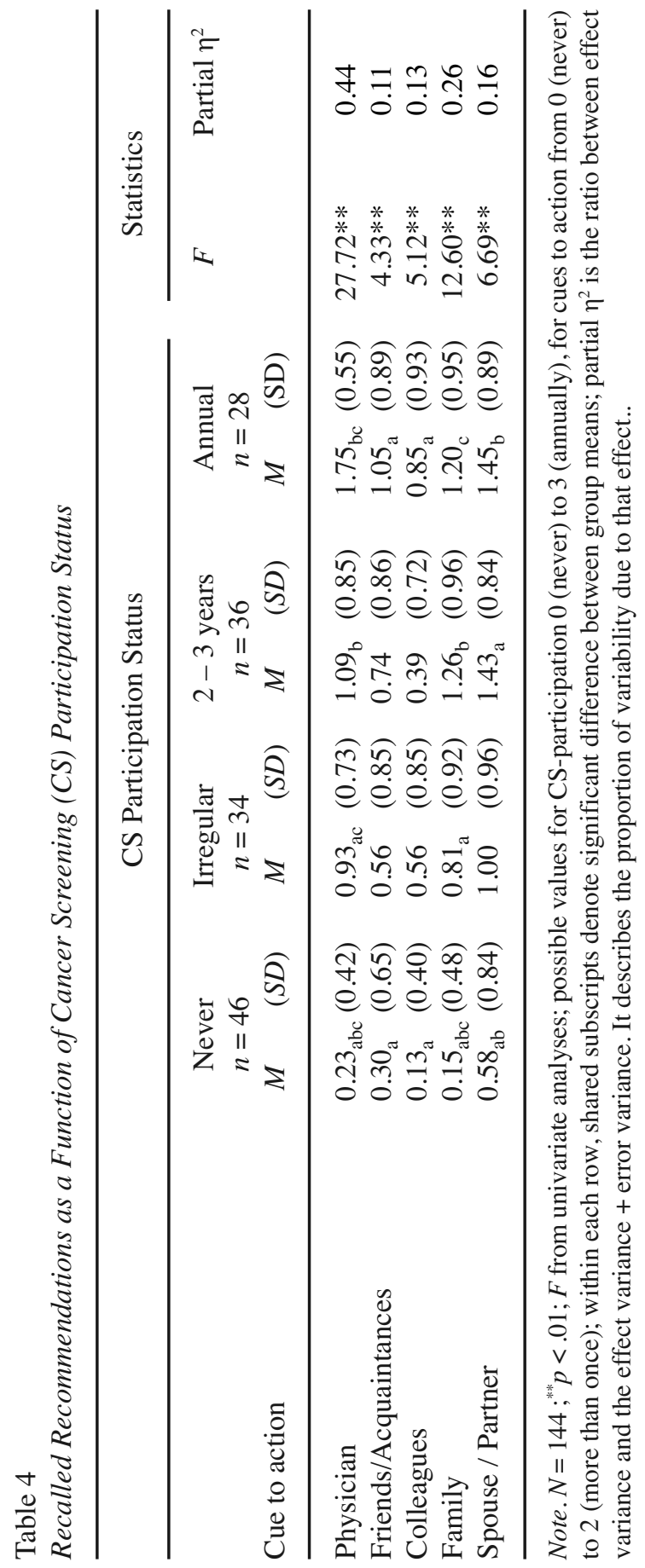


Bonferroni post-hoc comparisons (also Table 3) revealed significant differences in mean recall of information from health insurance provider between non- and annual participants. The annual participants' mean on this variable was 1.86 indicating a high proportion of men in this group to have received this type of information more than once. Information from physician was received significantly more often by participants attending every two-to-three years and annual participants (highest mean) in comparison to non-participants. No significant differences in recall of information from print media, television or radio or health promotion fair were observed as a function of CS participation. Recall of media cues was high in all groups (means ranging from 1.33 to 1.92) suggesting the majority of men including non-participants had received information from media sources more than once (ceiling effect). Recall of information from health promotion fair was low in all groups (flooring effect). Although mean recall of information from health insurance provider and physician was higher for annual participants in comparison to less regular participants, these differences failed to reach significance.

\section{Cues to Action II - Recommendations}

Again as in the first MANOVA, the combined dependent variables (recommendation by) were significantly related to regularity of CS participation, $F(15,282)=6.18$, $p<0.001$, partial $\eta^{2}=0.23$. Subsequent univariate ANOVAs revealed significant differences in recall of all recommendation cues as a function of CS participation status. The results of this analysis are displayed in Table 4.

The strongest association was observed for physician's recommendation, with a partial $\eta^{2}$ of 0.44 followed by recommendation by a family member (other than partner/spouse). By comparison, the partial $\eta^{2}$ were much smaller for the remaining three cues to action.

Inspection of the means for each category of the respective cues to action generally showed a gradual increase of cue to action exposure as CS participation status became more regular with the highest mean recall in the annual participation group, although slight deviations from this rule occurred for recommendations by colleagues and family members. Bonferroni post-hoc tests (also Table 4) revealed that mean scores were significantly different from each other among several categories of cues to action as a function of CS participation status. Men who had never attended a CS had significantly lower mean scores on physician's recommendation in comparison to all other groups. Mean recall for annual participants was 1.75 indicating a high percentage of men who had received a recommendation more than once while the non-participants' mean of 0.2 suggests a large proportion of men reporting to never have received a recommendation by a physician. The difference between non-annual (every two to three years and irregular) and annual participation reached significance, too. Recall of cues from friends/acquaintances and colleagues were only significantly different between annual and non-participants. Significant differences in mean recall of recommendation by a family member other than spouse were observed between non-participants and all 


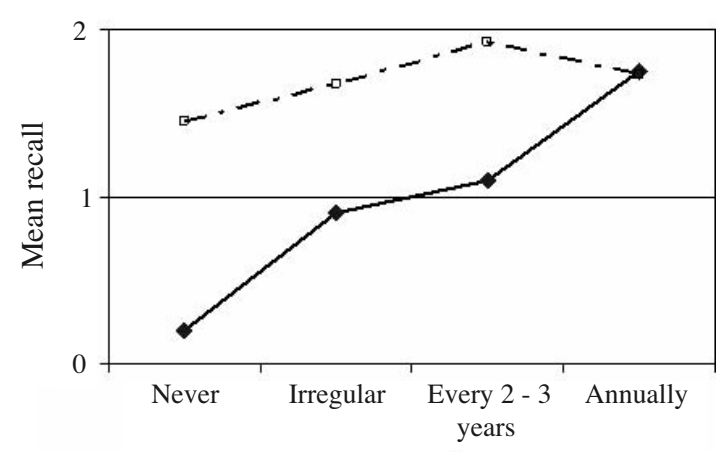

Figure 1.

Mean recall of two cues to action.

Note. Cues to action are physician's recommendation and information from print media. Possible values: $0=$ "never", $1=$ "once", $2=$ "more than once" as a function of cancer screening participation status (ranging from "never" to "annually"), $N=144$.

other groups. Regarding recommendation by spouse/partner, significant differences were only found between non-participation and participation every 2 to 3 years as well as annual participation.

Two important results of our analysis are illustrated in Figure 1: a) the saturation effect of information from media and $b$ ) the fact that recall of physician's recommendation differed clearly among the four groups.

\section{Multiple Regression of Cancer Screening Participation Status on All Cues to Action}

To assess which of the cues were most predictive of CS participation status a multiple regression analysis simultaneously entering all cues to action that were significantly correlated with CS participation (see Table 2) was conducted. Only physician's recommendation $(\beta=0.59, p<0.001)$ and recommendation by a family member $(\beta=$ $0.35, p<0.01$ emerged as significant predictors of CS participation (adjusted $R^{2}=.50$ ).

\section{Discussion}

The objective of the present study was to ascertain in a sample of men aged 45-70 which cues to action prompt men to undergo cancer screenings. The first study by means of structured interviews identified several cues to action as relevant triggers of cancer screening participation. Relevant sources of influence named by the sample included physician's recommendation, which was also reported by McCoy et al. (1995), Nivens et al. (2001) and Perkins et al. (1998), media coverage, also found by George and Flemming (2004), McKee (1994) and Raich et al. (1997) and recommendation by other persons (especially wife or partner) confirming George and Flemming's (2004) findings. Besides these cues to action already reported in the literature, information from the health insurance provider emerged as an additional cue to action. The second 
study investigated the relationships between these cues to action and participation status in another sample of men of the same age group. Frequency of exposure to cues to action (information from or recommendation by) was compared across four groups of men: Men who had never, men who had irregularly, men who had every two to three years, and men who had annually participated in cancer screenings.

Within the first group of cues to action, which included information from a variety of sources (print media, TV and radio, health insurance provider, health promotion fair and physician), significant differences as a function of CS participation status emerged only for information from health insurance provider and from physician. Mean recall for both cues increased as CS participation became more regular. Significant associations between receipt of personalized information from health insurance provider and prostate cancer screening were also reported by Holland, Bradley and Khoury (2005). Mean recall of information from health promotion fairs was low in all groups and not significantly different as a function of CS participation status. This type of campaign is fairly new and appears to have failed to exert its influence on screening behavior so far. On the other hand, information from and campaigns in print media, TV or the radio, were found to have reached most men in all groups. Unlike George and Flemming (2004) or Raich et al. (1997) who reported cues from the media to play a role in triggering screening behavior, we found a ceiling effect for this cue to action. Mean recall for information from the media (print and television/radio) was high in all groups and although somewhat lower for non-participants no significant differences were observed. In other words, irrespective of participation status, men in all groups appear to have received information about cancer screenings from the media on a regular basis. This may reflect saturation effects, i.e., if men are exposed to these cues too often they may not heed attention to them anymore. These campaigns may also fail to reach the men as a result of inappropriate designs. More research is needed to assess what men think of these media campaigns. Bennett and Murphy (1997) concluded that mass media campaigns are often atheoretical or use inappropriate psychological models. Psychology, however, has the potential to provide frameworks for successful media campaigns when relevant factors such as message content, appropriate sources of information, or communication within a social system are considered (Murphy \& Bennett, 2004). Similarly, the manner in which health related messages are framed has been shown to have an effect on how successful health campaigns reach the intended audience ( for a review, see Schneider, 2006).

Within the second set of cues to action (recommendations) significant differences in mean recall were observed for all cues as a function of participation status, although not all differences were significant when individual post-hoc comparisons were conducted. Personal recommendations of physicians and family members appear to be most effective in prompting men to participate in cancer screenings. Recommendations by friends, colleagues or family members were influential, too, albeit their means differed less markedly. A stronger association was observed for recommendations by relatives as opposed to non-relatives such as friends or colleagues. Taken together these are important findings suggesting to no longer rely on mainly media campaigns but to put stronger efforts into personal health behavior counseling. 
Mean recall of cues to action was generally highest for annual participants and for several cues their values indicated proximity to cue to action exposure more than once. Regular annual CS participation appears to be related to repeated exposure to some cues to action although we only found significant differences between annual and less regular attendance for physician's recommendation. This to some extent parallels Snell and Buck's (1996) finding of multiple interventions aimed at increasing physician's awareness of their role in conveying screening recommendations to be more successful than single interventions.

Multiple regression results pointed to physician's recommendation to be the strongest predictor of CS participation status, followed by the recommendation by other persons, particularly family members and wives. Although only physician's recommendation and recommendation by family members reached significance, the intercorrelations among the cues to action under investigation were high which is why the importance of the other cues that were significant in multivariate analysis of variance should not be disregarded.

Our study supports findings from other studies particularly about the important role the physician plays in providing the most relevant cue to action. It appears the best way to increase the number of men undergoing cancer screenings is by motivating more physicians to inform their male patients about cancer screenings. A problem with this approach is, however, that men as compared to women, especially those in the younger and middle age groups are more reluctant to seek advice and get help from health professionals (Mansfield et al., 2003). Bearing this in mind, health insurance providers should also increase their efforts at informing and motivating their clients. Information from this source was found an important cue to action in this study, a finding that has rarely been reported in the literature. This study also found some evidence that the frequency with which cues to action are encountered plays an important role, an aspect that had not been addressed by previous studies on cues to action.

There are some limitations to this study. First, we used convenience sampling, hence self-selection may have taken place and bias the results. Secondly, the data was assessed by self-report. Hall et al. (2004) demonstrated over-reporting of previous cancer screening participation in comparison to medical audit. However, other studies could demonstrate a high accuracy of self-reported cancer screening experience, when questionnaires were carefully phrased (Baier et al., 2000; Mandelson, LaCroix, Anderson, Nadel, \& Lee, 1999). Thirdly, the sample was positively skewed with regard to education, which makes generalizing the findings more difficult. In addition, the design was cross-sectional, and cues to action were assessed retrospectively. As pointed out by Rosenstock (1974, p. 6), in retrospective designs, it cannot be ruled out that cues to action are remembered better by people who have shown the specific action, whereas people who have not may have forgotten the cue to action (recall bias). However, not all cues to action differed as a function of participation status indicating that memory effects cannot solely be responsible for the results. Particularly for information from diverse media, a ceiling effect was detected. Today, it appears most men have been confronted with information from this source, but this is not associated with screening 
behavior. Saturation with information from this source or lack of quality of media campaigns may serve to account for this observation. For other cues to action significant differences were found across groups. These factors, particularly the recommendation of physicians, of family members, wives or partners and information by the health service provider appear to be important cues to action. In order to test whether exposure to certain cues really influences cancer screening behavior longitudinal and intervention studies are necessary. Also the assumed superiority of regular cue exposure deserves further investigation.

\section{References}

Aiken, L. S., West, S. G., Woodward, C. K., \& Reno, R. R. (1994). Health beliefs and compliance with mammography-screening recommendations in asymptomatic women. Health Psychology, 13(2), 122-129.

Altenhofen, L. (2005). Hochrechnung zur Akzeptanz von Gesundheitsuntersuchungen und Krebsfrüherkennungsuntersuchungen bei gesetzlich Versicherten [Extrapolation data regarding acceptance of health check-ups and early detection cancer screenings for the population of people covered by public health insurance]. Retrieved 06/02/06, from http://www.ziberlin.de/k_frueh_prog/downloads/Akzeptanz_KFU_GU_FOBT.pdf

Aoun, S., Donovan, R. J., Johnson, L., \& Egger, G. (2002). Preventive care in the context of men's health. Journal of Health Psychology, 7(3), 243-252.

Baier, M., Calonge, N., Cutter, G., McClatchey, M., Schoentgen, S., Hines, S., et al. (2000). Validity of self-reported colorectal cancer screening behavior. Cancer Epidemiology, Biomarkers \& Prevention, 9(2), 229-232.

Becker, M. H. (1974). The health belief model and personal health behavior. Health Education Monographs, 2(4), 324-508.

Bennett, P., \& Murphy, S. (1997). Psychology and health promotion. Buckingham: Open University Press.

Brown, M. L., Potosky, A. L., Thompson, G. B., \& Kessler, L. G. (1990). The knowledge and use of screening tests for colorectal and prostate cancer: data from the 1987 National Health Interview Survey. Preventive Medicine, 19(5), 562-574.

Burack, R. C., Gimotty, P. A., George, J., Stengle, W., Warbasse, L., \& Moncrease, A. (1994). Promoting screening mammography in inner-city settings: a randomized controlled trial of computerized reminders as a component of a program to facilitate mammography. Medical Care, 32(6), 609-624.

Centers for Disease Control and Prevention (CDC). (2004). Behavioral risk factor surveillance system survey data. Atlanta: Department of Health and Human Services, CDC.

Courtenay, W. H. (2000). Constructions of masculinity and their influence on men's well-being: A theory of gender and health. Social Science \& Medicine, 50(10), 1385-1401.

Courtenay, W. H. (2003). Key determinants of the health and well-being of men and boys. International Journal of Men's Health, 2(1), 1-30.

Curry, S. J., \& Emmons, K. M. (1994). Theoretical models for predicting and improving compliance with breast cancer screening. Annals of Behavioral Medicine, 16(4), 302-316.

Evans, R. E. C., Brotherstone, H., Miles, A., \& Wardle, J. (2005). Gender differences in early detection of cancer. Journal of Men's Health \& Gender, 2(2), 209-217. 
Federal Statistical Office. (2005). Statistical yearbook for the Federal Republic of Germany. Wiesbaden: Statistisches Bundesamt (Federal Statistical Office).

Finney-Rutten, L. J., \& Iannotti, R. J. (2003). Health beliefs, salience of breast cancer family history, and involvement with breast cancer issues: Adherence to annual mammography screening recommendations. Cancer Detection and Prevention, 27(5), 353-359.

George, A., \& Fleming, P. (2004). Factors affecting men's help-seeking in the early detection of prostate cancer: Implications for health promotion. Journal of Men's Health \& Gender, 1(4), 345-352.

Hall, H. I., Van Den Eeden, S. K., Tolsma, D. D., Rardin, K., Thompson, T., Hughes Sinclair, A., et al. (2004). Testing for prostate and colorectal cancer: comparison of self-report and medical record audit. Preventive Medicine, 39(1), 27-35.

Harrison, J. A., Mullen, P. D., \& Green, L. W. (1992). A meta-analysis of studies of the health belief model with adults. Health Education Research, 7(1), 107-116.

Holland, D. J., Bradley, D. W., \& Khoury, J. M. (2005). Sending men the message about preventive care: An evaluation of communication strategies. International Journal of Men's Health, 4(2), 97-114.

Klug, S. J., Hetzer, M., \& Blettner, M. (2005). Screening for breast and cervical cancer in a large German city: Participation, motivation and knowledge of risk factors. European Journal of Public Health, 15(1), 70-77.

Lerman, C., Trock, B., Rimer, B. K., \& Jepson, C. (1991). Psychological side effects of breast cancer screening. Health Psychology, 10(4), 259-267.

Mandelson, M. T., LaCroix, A. Z., Anderson, L. A., Nadel, M. R., \& Lee, N. C. (1999). Comparison of self-reported fecal occult blood testing with automated laboratory records among older women in a health maintenance organization. American Journal of Epidemiology, 150(6), 617-621.

Mansfield, A. K., Addis, M. E., \& Mahalik, J. R. (2003). "Why won't he go to the doctor?”: The psychology of men's help seeking. International Journal of Men's Health, 2(2), 93-109.

McCoy, C. B., Anwyl R. S., Metsch, L. R., Inciardi, J. A., Smith, S. A., \& Correa, R. (1995). Prostate cancer in Florida: knowledge, attitudes, practices, and beliefs. Cancer Practice 3(2), 88-93.

McCreary, D. R., Gray, R. E., \& Grace, S. L. (2006). Gender differences in cancer mortality risk perceptions and screening behaviors among adults 40-60 tears of age. International Journal of Men's Health, 5(1), 53-63.

McKee, J. M. (1994). Cues to action in prostate cancer screening. Oncology Nursing Forum, 21(7), 1171-1176.

Murphy, S., \& Bennett, P. (2004). Health psychology and public health: Theoretical possibilities. Journal of Health Psychology, 9(1), 13-27.

Nielsen, C. C. (1990). Women's use of mammographic screening: the role of information, cues, and reinforcement. Connecticut Medicine, 54(7), 374-377.

Nivens, A. S., Herman, J. A., Weinrich, S. P., \& Weinrich, M. C. (2001). Cues to participation in prostate cancer screening: A theory for Practice. Oncology Nursing forum, 28(9), 1449-1456.

Perkins, J. J., Sanson-Fisher, R. W., Clarke, S. J., \& Youman, P. (1998). An exploration of screening practices for prostate cancer and the associated community expenditure. British Journal of Urology, 82(4), 524-529.

Raich, P. C., Zoeter, M. A., Hagan, M., Carparelli, S., Olstad, K. A., Newman, C., et al. (1997). Perception of preventive health needs in a prostate-cancer screening population: A preliminary report. Journal of Cancer Education, 12(4), 224-228. 
Rosenstock, I. M. (1966). Why people use health services. Milbank Memorial Fund Quarterly, 44(3), 94-124.

Rosenstock, I. M. (1974). Historical origins of the health belief model. In M. H. Becker (Ed.), The health belief model and personal health behavior (pp. 1-8). Thorofare, NJ: Charles B. Slack.

Rosenstock, I. M. (2000). Health belief model. In A. E. Kazdin (Ed.), Encyclopedia of psychology (Vol. 4, pp. 78-80). Washington, DC: American Psychological Association.

Schneider, T. R. (2006). Getting the biggest bang for your health education buck: Message framing and reducing health disparities. American Behavioral Scientist, 49(6), 812-822.

Snell, J. L., \& Buck, E. L. (1996). Increasing cancer screening: A meta-analysis. Preventive Medicine, 25(6), 702-707.

Stein, J. A., Fox, S. A., Murata, P. J., \& Morisky, D. E. (1992). Mammography usage and the health belief model. Health Education Quarterly, 19(4), 447-462. 
Copyright of International Journal of Men's Health is the property of Men's Studies Press and its content may not be copied or emailed to multiple sites or posted to a listserv without the copyright holder's express written permission. However, users may print, download, or email articles for individual use. 